Prepared for the U.S. Department of Energy

under Contract DE-AC05-76RL01830

\title{
Modeling of GE Appliances: \\ Final Presentation
}

JC Fuller

B Vyakaranam

SM Leistritz

GB Parker

January 2013

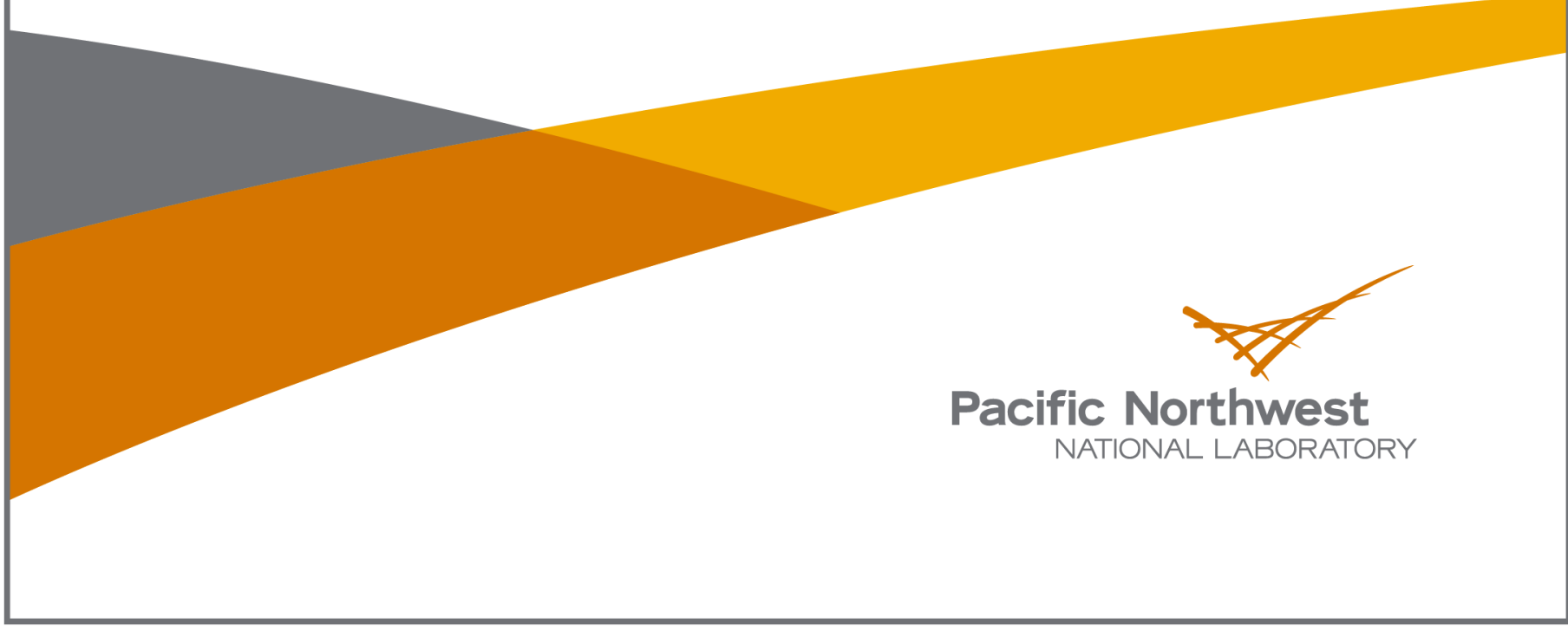




\title{
DISCLAIMER
}

This report was prepared as an account of work sponsored by an agency of the United States Government. Neither the United States Government nor any agency thereof, nor Battelle Memorial Institute, nor any of their employees, makes any warranty, express or implied, or assumes any legal liability or responsibility for the accuracy, completeness, or usefulness of any information, apparatus, product, or process disclosed, or represents that its use would not infringe privately owned rights. Reference herein to any specific commercial product, process, or service by trade name, trademark, manufacturer, or otherwise does not necessarily constitute or imply its endorsement, recommendation, or favoring by the United States Government or any agency thereof, or Battelle Memorial Institute. The views and opinions of authors expressed herein do not necessarily state or reflect those of the United States Government or any agency thereof.

\author{
PACIFIC NORTHWEST NATIONAL LABORATORY \\ operated by \\ BATTELLE \\ for the
}

UNITED STATES DEPARTMENT OF ENERGY

under Contract DE-AC05-76RL01830

Printed in the United States of America

Available to DOE and DOE contractors from the Office of Scientific and Technical Information,

P.O. Box 62, Oak Ridge, TN 37831-0062; ph: (865) 576-8401 fax: (865) 576-5728 email: reports@adonis.osti.gov

Available to the public from the National Technical Information Service, U.S. Department of Commerce, 5285 Port Royal Rd., Springfield, VA 22161

ph: (800) 553-6847 fax: (703) 605-6900

email: orders@ntis.fedworld.gov online ordering: http://www.ntis.gov/ordering.htm

This document was printed on recycled paper. 


\section{Modeling of GE Appliances: Final Presentation}

JC Fuller

B Vyakaranam

SM Leistritz

GB Parker

January 2013

Prepared for

the U.S. Department of Energy

under Contract DE-AC05-76RL01830

Pacific Northwest National Laboratory

Richland, Washington 99352 


\section{Table of Contents}

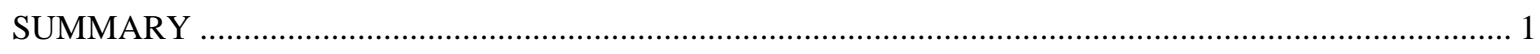

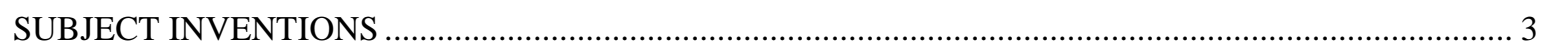

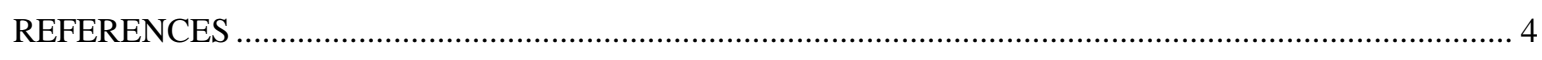

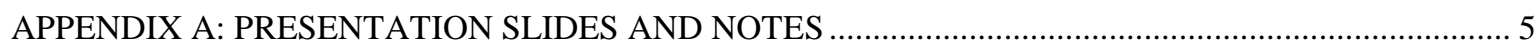




\section{Summary}

The Energy Information Administration (EIA) estimates that electricity use will increase by more than 30 percent by 2035, and that residential electricity usage will increase by 23 percent [1]. During this time, peak electricity demand is expected grow at an even greater rate, requiring significant investment in system capacity. In addition, increased penetration of intermittent renewable resources will increase system variability, requiring additional resources to mitigate the variability associated with generator output [2]. Widespread adoption of demand response (DR) enabled appliances, thermostats, and other demand-side resources can result in significant reduction to peak electrical demand and provide potential grid stabilization benefits. The key to adoption is to provide this resource at a cost commensurate with traditional grid capabilities, and to appropriately share both the costs and the benefits between the consumer and the service provider (i.e., the utility). However, the business model for investing in demand-side resources cannot be determined without an estimation of the possible technical benefits and how those benefits translate to monetary value in current electrical market structures.

GE Appliances has developed a line of appliances that will have the capability of offering several levels of demand reduction actions based on information received from the utility grid, often in the form of price or grid status. However due to a number of factors, including the number of DR-enabled appliances available at any given time, the reduction of diversity factor due to the synchronizing control signal, and the percentage of consumers who may override the utility signal, it can be difficult to predict the aggregate response of a large number of residences. The effects of these behaviors have been modeled and simulated in the Pacific Northwest National Laboratory (PNNL) developed open-source software, GridLAB-D ${ }^{\mathrm{TM}}$ [3], including evaluation of appliance controls, improvement to current algorithms, and development of aggregate control methodologies. The results of these simulations provide an estimation of the possible technical benefits (e.g., peak load reduction) attributable to smart appliances, but do not describe the monetary value of these services.

This report is the final in a series of three reports funded by U.S. Department of Energy Office of Electricity Delivery and Energy Reliability (DOE-OE) in collaboration with GE Appliances' through a Cooperative Research and Development Agreement (CRADA) to describe the potential of GE Appliances' DR-enabled appliances to provide benefits to the utility grid. The first report described the modeling methodology used to represent the GE appliances in the GridLAB-D simulation environment and the estimated potential for peak demand reduction at various deployment levels [4]. The second report explores the monetary value of potential grid services (e.g., peak reduction or frequency regulation) provided by DR-enabled appliances in various U.S. energy markets. The third report was designed to explore the technical capability of aggregated group actions to positively impact grid stability, including frequency and voltage regulation and spinning reserves, and the impacts on distribution feeder voltage regulation, including mitigation of fluctuations caused by high penetration of photovoltaic distributed generation. Unfortunately, funding constraints for this research led to early termination and only 
initial results are available. PowerPoint slides, including author's notes, presenting some of the initial results are included in Appendix A. These results should not be considered conclusive, but rather very early indicators of possibilities. Much additional work is needed.

These slides show results from GridLAB-D simulations that were used to explore how localized control of GE smart appliances could be used for system benefit. A few different types of control were explored. Appliance load reduction was used to mitigate the effects on local system voltage due to cloud transients in high solar photovoltaic (PV) feeders. In feeders with high penetration solar PV, a passage of a cloud can rapidly reduce the power output of the PV units, causing short term voltage fluctuations. Initial studies show that the appliances are able to correctly and efficiently respond using a simple deadband-like control while only monitoring local voltage. The effects on voltage were relatively minimal, with a maximum change in voltage on the order of $0.5 \mathrm{~V}$ at the household meter when all devices respond. This is due to the relatively low coincidence of low voltage events and appliance activity - peak load is driven by appliances being mostly active, however the low voltage was due to high penetration solar PV and does not necessarily coincide with appliance activity. Additionally, voltage fluctuations can be more easily corrected with reactive power compensation than real power compensation. Again, these results should be considered very initial. Future work should investigate the potential benefits of integrating the appliance control with four-quadrant inverter controls and determine the value of such integrated systems for mitigating cloud transient behavior (or other short term voltage transient behaviors). Additionally, the long term effects on appliance lifetime should be evaluated and consumers appropriately compensated for the use of their devices. Much work needs to be done to investigate these areas.

In addition to voltage control, response to frequency deviations was explored. Again, localized control and sensing was employed. A simple droop-like control was designed to respond to frequency deviations by reducing demand during low frequency events. By using local randomization, no communication from a central actor is needed - devices can locally sense the frequency and make decisions about whether the device should respond. In aggregate, the devices reduce a greater amount of load for greater deviations from a specified frequency threshold. Initial indications are that the smart appliances are quite capable of responding to frequency deviations, reducing demand by $15-30 \%$ over very short periods of time ( $\sim$ seconds to minutes). Additionally, because the load reductions are of such a brief period, overall load behavior is not significantly affected and no rebound is observed. Again, these results are very initial and additional work needs to performed to understand the type of control that should be utilized (centralized vs. decentralized), thresholds for activation, and how to incentive customers, among other issues. However, early indications are that smart appliances could provide significant frequency regulation services. 


\section{Subject Inventions}

No Subject Inventions were derived by PNNL under this CRADA. 


\section{References}

[1] "U.S. Energy Information Administration". September 2011. [Online]. Available: http://www.eia.gov.

[2] B. Perlstein, et al., "Potential Role of Demand Response Resources in Maintaining Grid Stability and Integrating Variable Renewable Energy under California's 33 Percent Renewable Portfolio Standard", prepared for California's Demand Response Measurement and Evaluation Committee by Navigant Consulting, Inc., July 20, 2012.

[3] “GridLAB-D”. September 2011. [Online]. Available: http://www.gridlabd.org.

[4] J. C. Fuller, et al., "Modeling of GE Appliances: Peak Demand Reduction", PNNL-21358, Pacific Northwest National Laboratory, Richland, WA, 2012.

[5] J. C. Fuller, G. B. Parker, "Modeling of GE Appliances: Cost Benefit Study of Smart Appliances in Wholesale Energy, Frequency Regulation, and Spinning Reserve Markets", PNNL-22128, Pacific Northwest National Laboratory, Richland, WA, 2012.

[6] D. Hammerstrom, et al., "Pacific Northwest GridWise Testbed Demonstration Projects Part II. Grid Friendly Appliance Project”, PNNL-17079, Pacific Northwest National Laboratory, Richland, WA, 2007. 
Appendix A: Presentation Slides and Notes 


\section{Smart Appliance Benefits}




\section{Why Smart Appliances?}

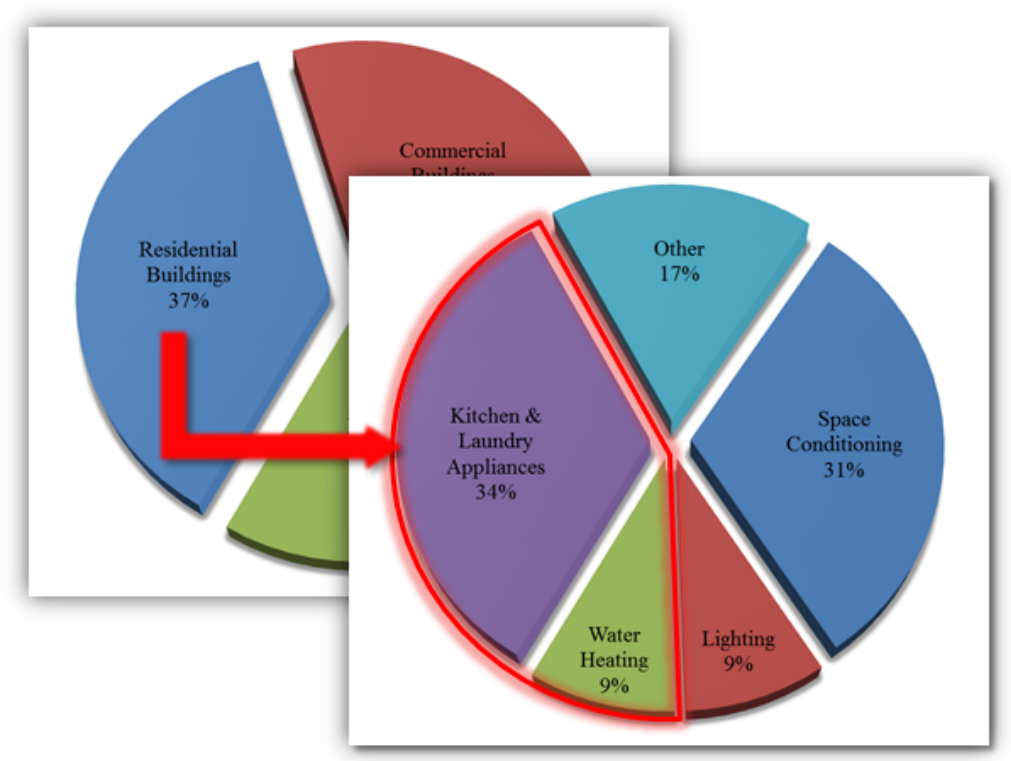

- $\sim 15 \%$ of all U.S. electricity is consumed by residential appliances

- $\$ 900 /$ year / household

- Traditional focus has been on energy efficiency $(\mathrm{kWh})$

- Greater focus on load reduction $(\mathrm{kW})$ for:

- Peak reduction

- Frequency / regulation services

- Operational reserves

*http:/www.epa.gov/greenbuilding/pubs/gbstats.pdf(2009)

*EIA, Residential Energy Consumption Survey 2001 


\section{Why Smart Appliances?}

- Appliances are $\sim 1 / 3$ of residential peak demand (or more)

- Represents a significant untapped resource for peak reduction

- And also provides a more consistent resource (than the more commonly used HVAC)

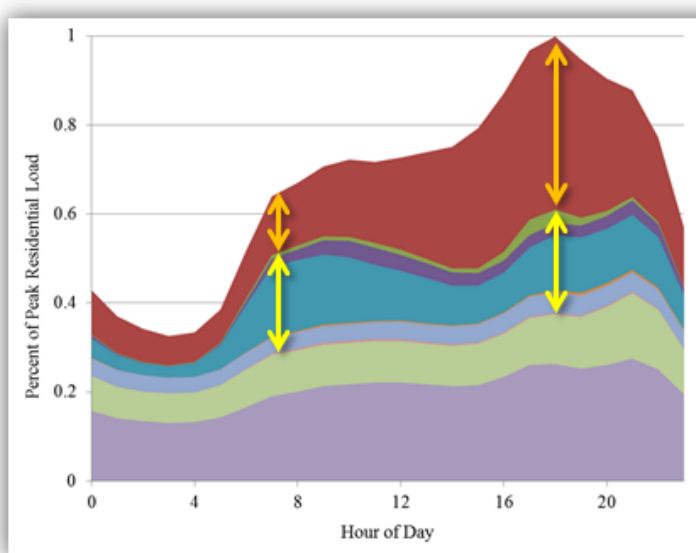

- HVAC

= RangeOven

- ClothesDryer

- Waterheater

$=$ Dishwasher

$=$ Refrigerator

$=$ ClothesWasher

= Lights/Plugs

$=$ Other

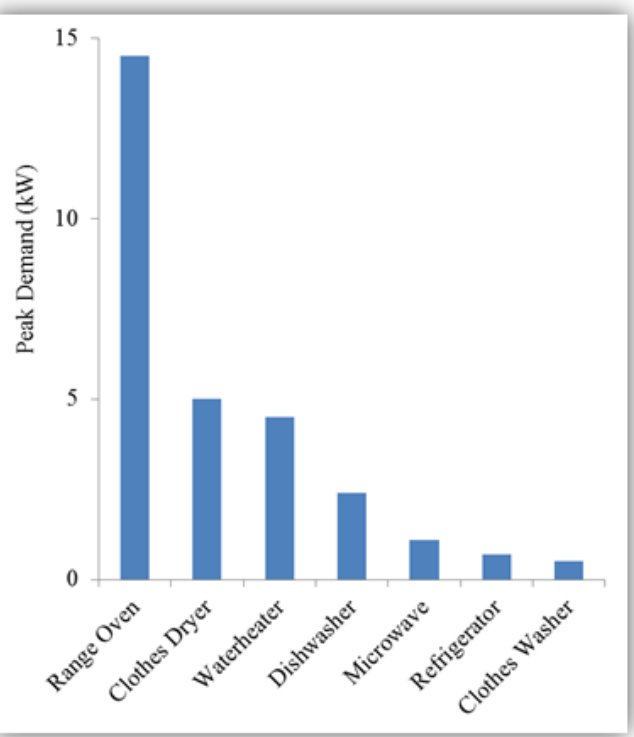




\section{Potential Benefits}

- Peak Reduction / Peak Shifting

- Increased system reliability

- Reduced system-wide energy costs and capital investment

- Customers save money (TOU, CPP)

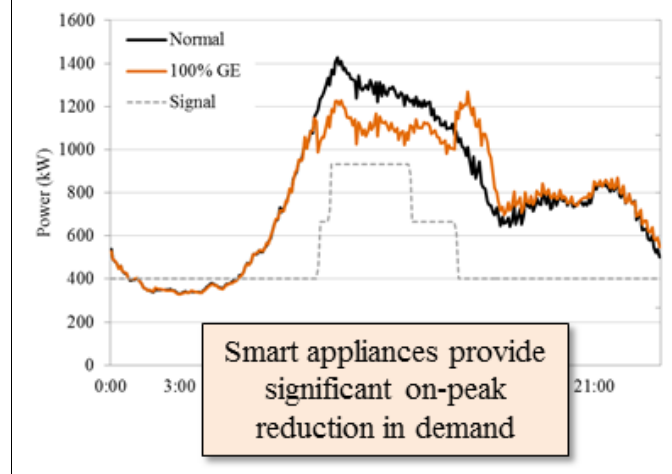

- Individual device reduction is relatively small, but aggregated effect can be significant

- Reduces feeder peak $\sim 5 \%$ at $25 \%$ penetration ${ }^{1}$

- Reduces feeder peak $\sim 1 \%$ at $5 \%$ penetration ${ }^{1}$ 


\section{Potential Benefits}

- Long term ( $\sim 4-6$ hours) reductions cause some negative effects (rebound effect)

- Delayed process eventually has to be recovered

- But effects can be mitigated with built-in control strategies
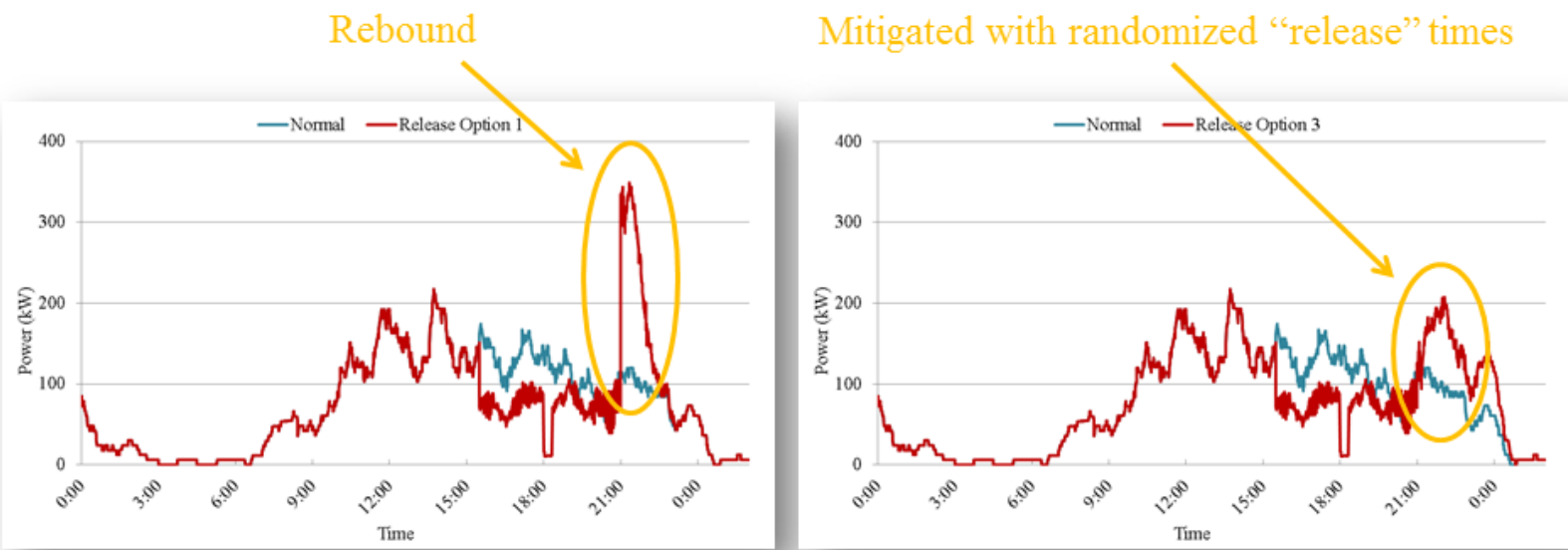


\section{Potential Benefits}

- Potential for ancillary services

- Operational reserves ("spinning" / "non-spinning")

- Frequency regulation

- Voltage regulation

- Short term reductions cause little to no rebound

- Difficult to increase load to perform down-regulation

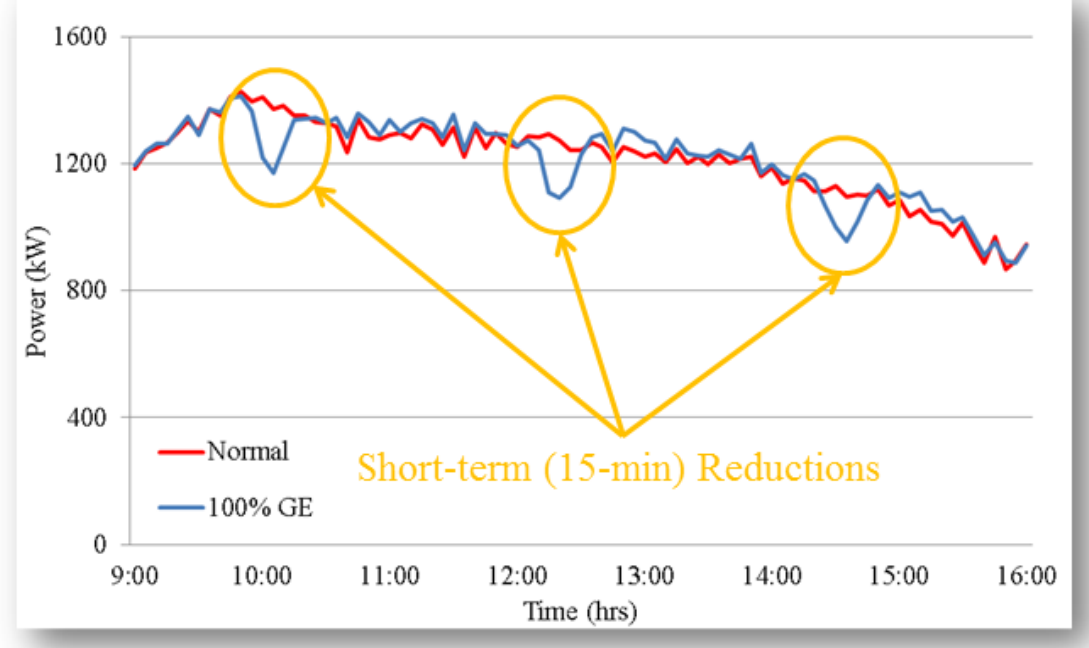




\section{Customer / Utility Value}

- Individual benefits may not provide enough value for customers or utilities to invest in technology

- Combination of a few (or all) provides multiple revenue streams for both the customer and the utility

- Keys to success will be to determine:

- How to combine values effectively

- How to structure markets to accept appliances as resources 


\section{Keys to Successful Adoption}

- Easy-to-Use

- Normal operation plus two additional modes

- DR- or ES-mode reduces power and energy consumption during peak load periods, while maintaining basic functionality

- Deferral allows the appliance to delay operation until a later time (N/A water heaters and refrigerators - little human interaction)

- Informing the customer

- Display panel shows the customer the current relative price of electricity

- Automated, but with consumer choice

- They can always override default operation

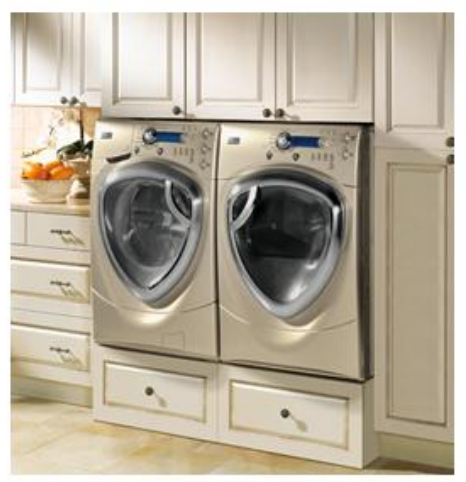




\section{Individual Appliance Operations}

\section{High}

Heat Pump

Water Heater

- Tariff shows on display

- Only operates in HP mode

- Provides enough hot water for most "normal" uses

Clothes Dryer - Tariff shows on display

- Enters ES-mode (10\% less energy consumed, peak demand reduced by $50 \%$ )*

Clothes

Washer
- Tariff shows on display

- Hot water demand reduced*

\section{Critical}

- Tariff shows on display

- Only operates in HP mode

- Setpoint is lowered to reduce demand

- Tariff shows on display

- Heat coils turned off temporarily, but drum continues to turn*

- Enters ECO-mode*

- Tariff shows on display

- Hot water demand turned off*

*Customer can always choose to (1) use pre-selected operation, (2) defer usage to another time period, or (3) override all settings and operate in normal mode. 


\section{Individual Appliance Operations}

\section{High}

- Tariff shows on display

- Cycle is delayed until Normal prices*

\section{Critical}

- Tariff shows on display

- Cycle is delayed until Normal prices*

- Heating coil(s) turned off*

Refrigerator - Tariff shows on display

- Freezer set point is slightly

- Sweat heaters are turned off raised for a short time

- Defrost cycle is deferred to later period

Range Oven

- Tariff shows on display

- Self-clean disabled*
- All responses are automated

- Tariff shows on display

- Hot water demand turned off*

* Customer can always choose to (1) use pre-selected operation, (2) defer usage to another time period, or (3) override all settings and operate in normal mode. 


\section{How much peak reduction?}

- Difficult to quantify - very dependent on time of day, climate region, TOU/CPP signal used, penetration levels, etc.

- Table shows approximation from PNNL studies on a CA feeder ${ }^{1}$

\begin{tabular}{lcc}
\hline & \multicolumn{2}{c}{ Peak Reduction } \\
\hline Electric Dryer & $\sim 100$ s of $\mathrm{kW}$ & $\sim 10 \%$ \\
Clothes Washer & $\sim 1 \mathrm{~s}$ of $\mathrm{kW}$ & $<1 \%$ \\
Dishwasher & $\sim 10 \mathrm{~s}$ of $\mathrm{kW}$ & $\sim 1-2 \%$ \\
Hybrid Water Heater & $\sim 100 \mathrm{~s}$ of $\mathrm{kW}$ & $\sim 10 \%$ \\
Electric Range & $\sim 10 \mathrm{~s}$ of $\mathrm{kW}$ & $\sim 1-2 \%$ \\
Refrigerator & $\sim 10 \mathrm{~s}$ of $\mathrm{kW}$ & $\sim 5 \%$ \\
Total Reduction & $\sim 100 \mathrm{~s}$ of $\mathrm{kW}$ & $\sim 25-30 \%$ \\
\hline
\end{tabular}

On a $\sim 2 \mathrm{MW}$ peak demand test feeder simulated in GridLAB-D with $100 \%$ penetration of responsive appliances, 4-6 hour CPP 


\section{Capturing additional benefits}

- Appliances are capable of fast action reduction

- On the order of $20-30 \%$ (or greater) reduction within minutes

- Spinning reserve, frequency regulation, voltage regulation, etc.

- Short term reductions (e.g., 5-15 minutes) have little to no effect on customer experience

- Can be performed with relatively simple control and sensing actions (dead band or droop-like control)
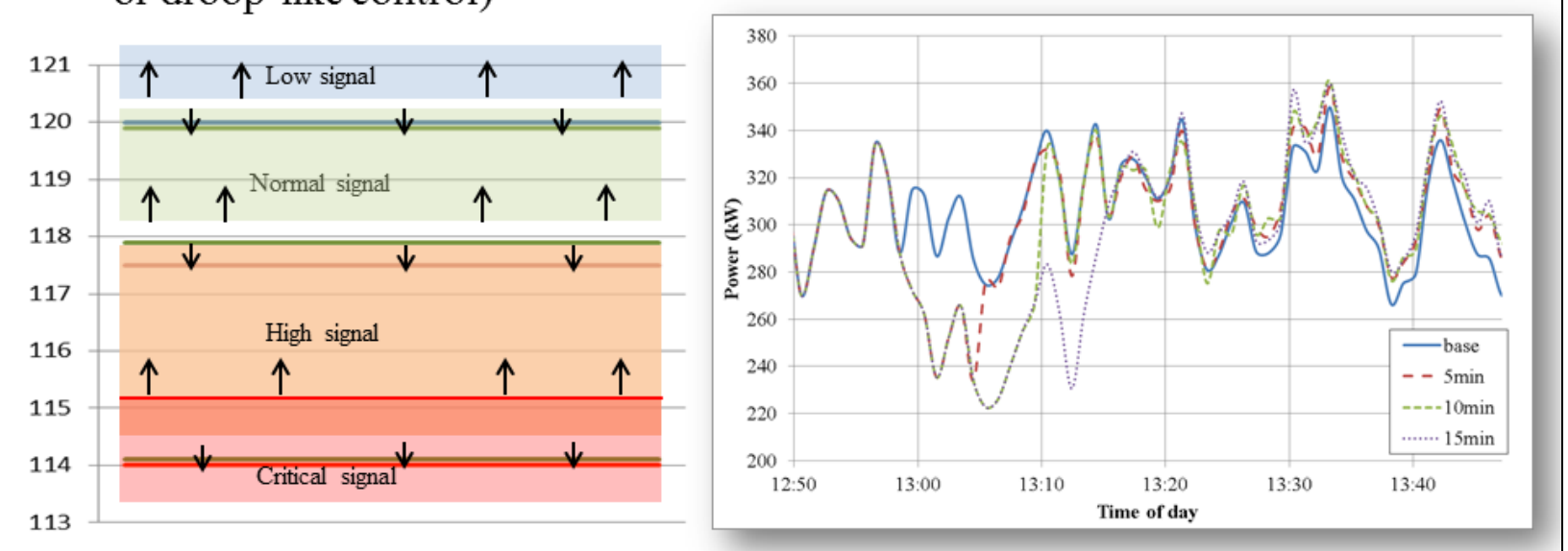

\section{NOTES:}

Simple deadband control for either frequency or voltage using localized sensing requires no additional communication systems.

There are some concerns as stability and reliability of the entire grid system come into question, but individually, appliances can respond correctly to the prescribed signals in aggregate. 


\section{Business Case for Smart Appliances}

- By capturing multiple revenue streams (wholesale energy, frequency regulation, spinning reserve), payback time can be decreased

- Cost needs to be evaluated as a function of the lifetime of the appliance (not in annual terms)

- Some appliances do not provide enough benefits to justify cost

Annual savings ( $\$$ and $\mathrm{kWh}$ ) for an average household in NYISO and PJM.

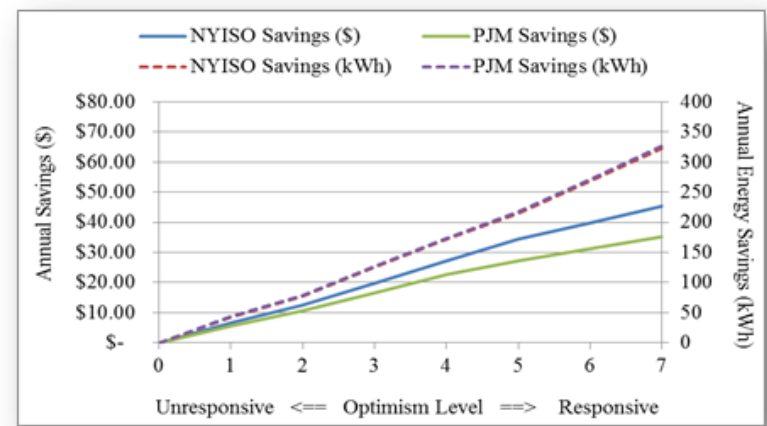

Lifetime savings for an average household by appliance in NYISO.

\begin{tabular}{|l|c|cc|}
\hline & $\begin{array}{c}\text { Average Lifetime of } \\
\text { Appliance (years) }\end{array}$ & Lifetime Savings (\$) \\
\hline Clothes Dryer & 14 & $\$$ & 71.50 \\
\hline Clothes Washer & 12 & $\$$ & 46.82 \\
\hline Dishwasher & 12 & $\$$ & 65.01 \\
\hline Food Preparation & 15 & $\$$ & 9.12 \\
\hline Freezer & 16 & $\$$ & 23.36 \\
\hline HVAC & 14 & $\$$ & 324.59 \\
\hline Lights and Plugs & - & & - \\
\hline Refrigerator & 14 & $\$$ & 20.83 \\
\hline Water Heater & 14 & $\$$ & 226.84 \\
\hline Total & - & $\$$ & 788.07 \\
\hline
\end{tabular}

${ }^{2}$ Modeling of GE Appliances in GridLAB-D: CostBenefit Study of Smart Appliances in Wholesale Energy, Frequency Regulation, and Spinning Reserve Markets, PNNL-22128

\section{NOTES:}

Certain appliances, particularly HVAC systems and water heaters are "low hanging fruit" for participation, but over the lifetime of the appliances, clothes dryers and washers, and dishwashers, and to a lesser degree, freezers and refrigerators provide additional savings. Food prep devices do not provide significant savings. 


\section{Conclusions}

- Smart appliances are capable of providing significant system benefits - both locally and globally.

- Long term reductions need additional controls to mitigate rebound.

- Short term reductions have little to no effect on customer experience and no rebound.

- To fully capture the value of smart appliances, multiple revenue streams and applications must be merged. 
Additional Slides 


\section{Frequency controller}

\section{NOTES:}

This control method aims at reducing demand during periods of high grid stress, specifically when frequency dips below a pre-determined threshold. A simple "droop" like control is used to diversify the behavior of the appliances in the system, while still relying on only localized sensing and decision making. Early indications are that the appliances can provide significant short term reductions (minimally 20-30\%) with little to no effect on load behavior or consumer experience. However, much work needs to be done to understand how such controls might affect the overall stability of the system. 


\section{WECC frequency probability}

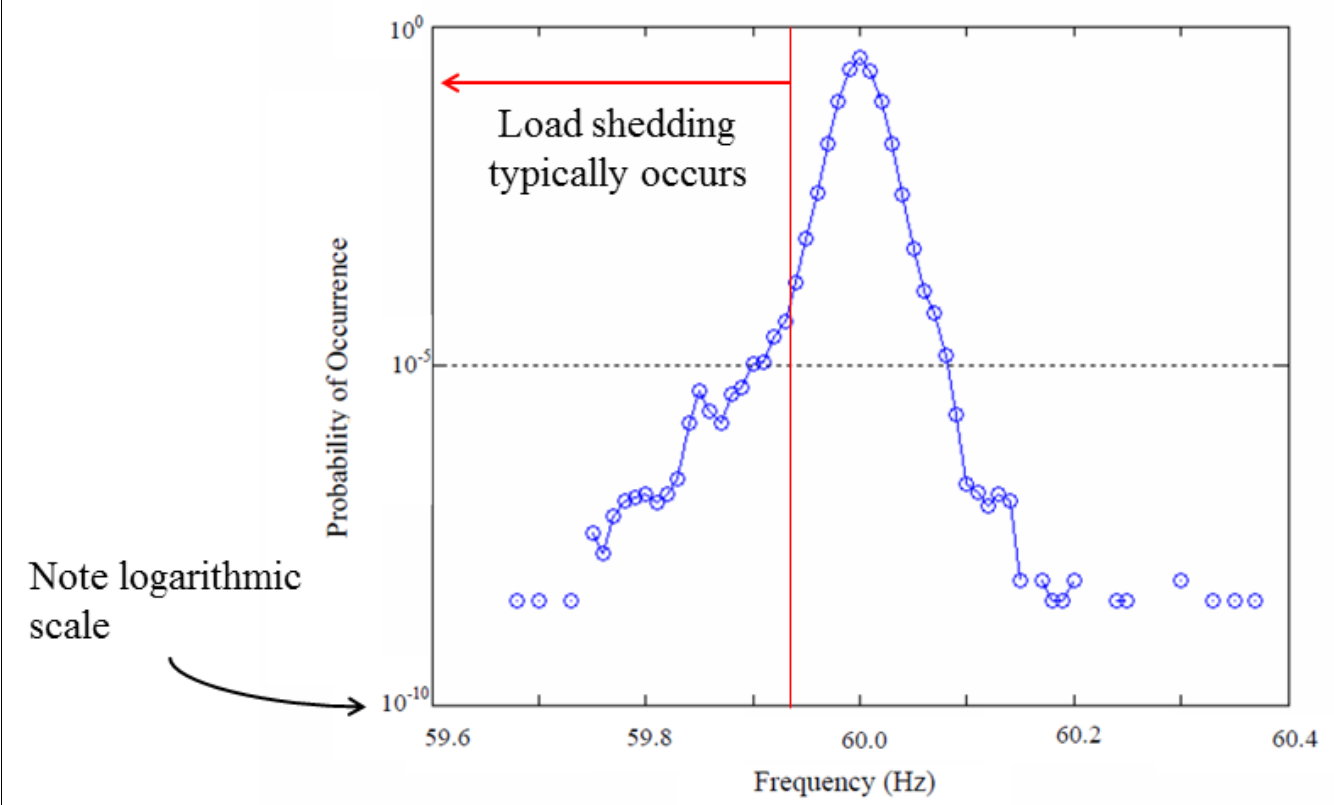

Figure 1.1. WECC Frequency Histogram Using Data Collected by PNNL from 2002 to 2005

\section{NOTES:}

This figure was taken from: Pacific Northwest GridWise ${ }^{\mathrm{TM}}$, Part II: Grid Friendly ${ }^{\mathrm{TM}}$ Appliance Project [6].

For example, mandatory load shedding may occur at $59.93 \mathrm{~Hz}$ if deviation is $>10$ minutes. Shorter time frames are used for further deviations. However, rules for load shedding vary in different balancing authorities.

The events are relatively rare, but very important to respond to quickly and reliably when it happens to prevent system break-up. 


\section{Local Response to Frequency Deviations}

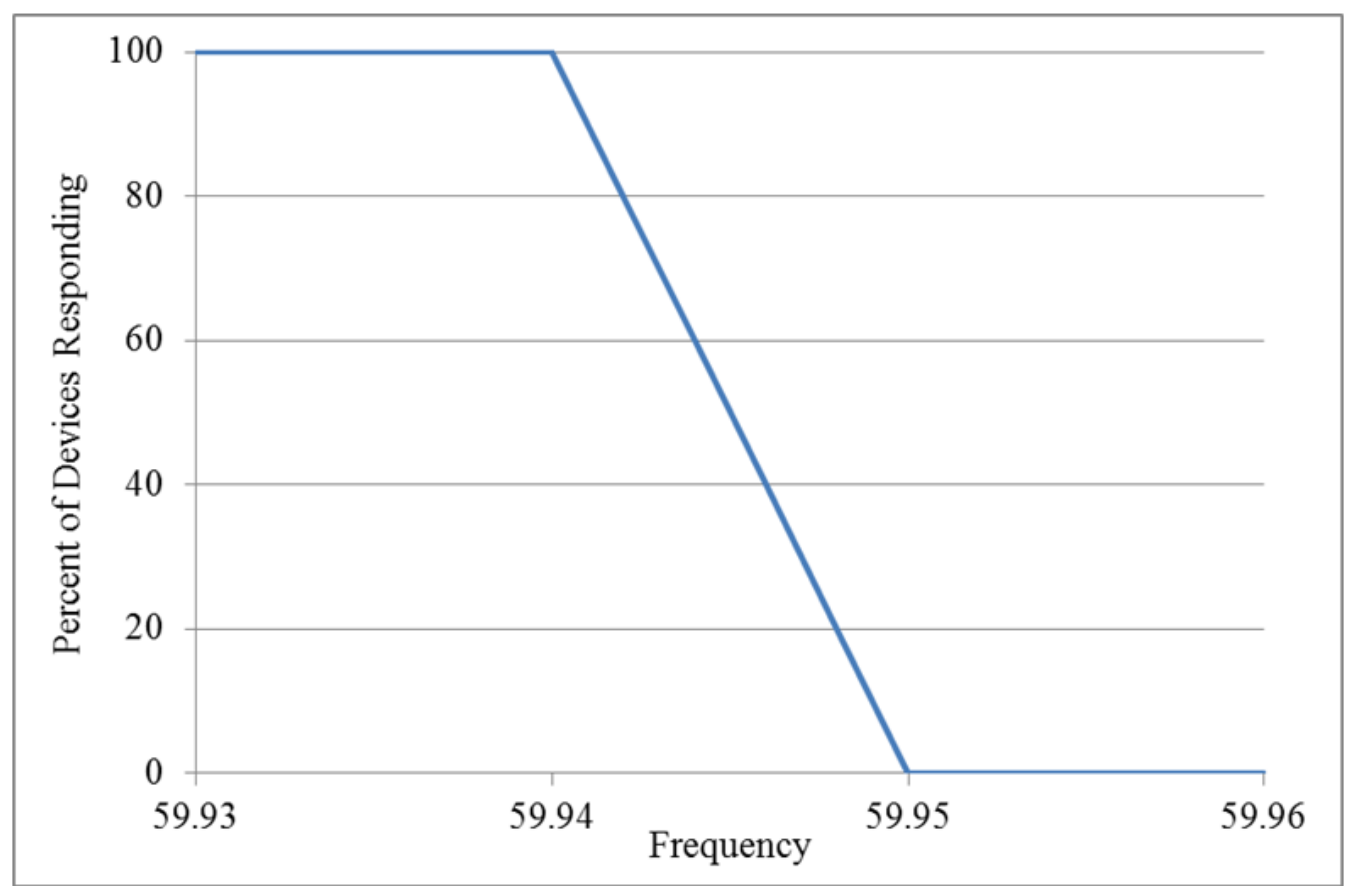

\section{NOTES:}

This type of control is analogous to "droop" control in generator assets. Assumptions can be made about what frequency the response starts or how responsive the devices are (i.e., the shape or slope of the curve). Some of these concepts are captured in Grid Friendly Appliances using more rigorous methodology.

In a given 5-minute (or 10 or other) interval, each appliance draws a uniform random number (RN) between 0 and 1 . If $\mathrm{RN}$ is less than the $y$-axis value corresponding to the current frequency, then the device shuts off. For example, if frequency were 59.945, the percent of devices desired to respond is $50 \%$. Therefore, any device that draws a RN less than 0.5 will respond and turn off. This method allows each device to locally make its own decision using local information, while in aggregation, respond in an understandable manner. It should be noted that there is a certain amount of (justifiable) trepidation on the part of grid operators with the widespread adoption of these type of controls. For example, if all devices are located in the North end of the WECC during a frequency deviation, but the load reduction is needed in the South, they may exacerbate stressed grid conditions. Further research is needed to understand how to fully use and control these devices when widespread. However, these examples are used to show the possibilities. 


\section{Frequency power response}

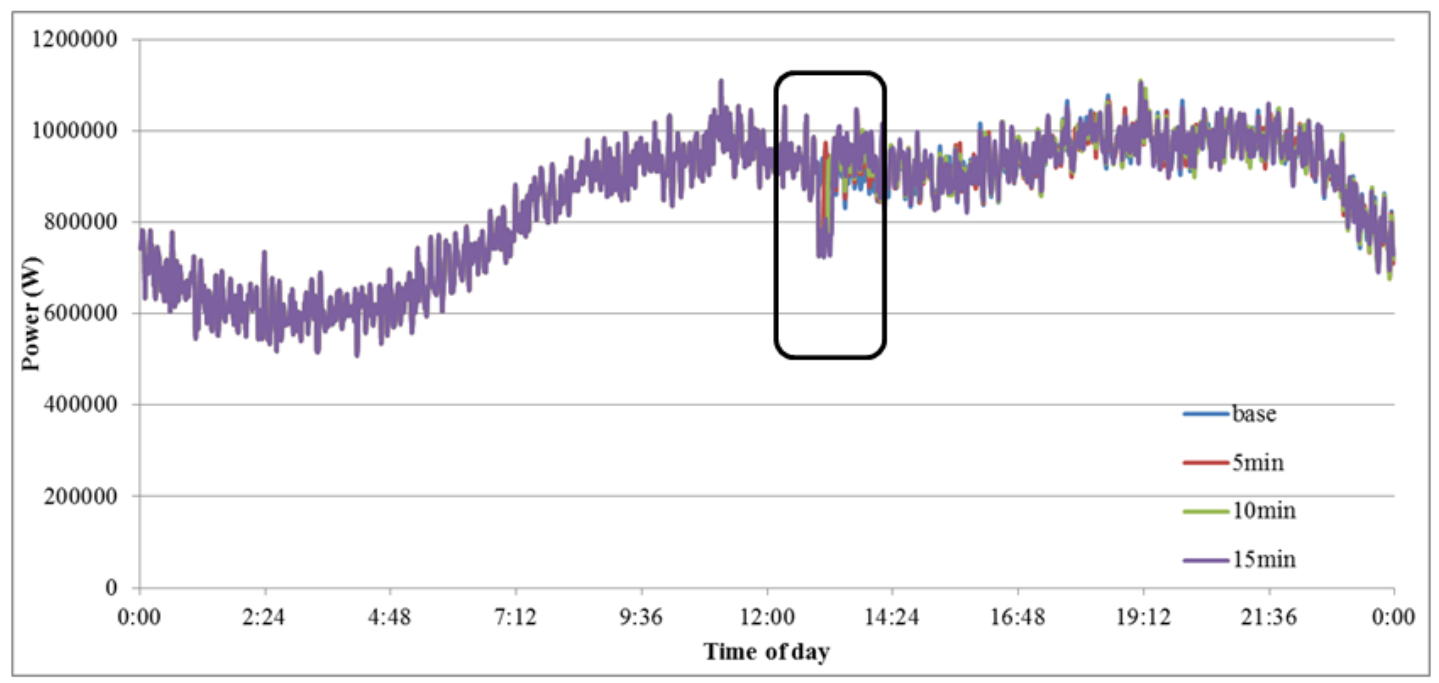

For 5, 10 and 15 min intervals

\section{NOTES:}

Total feeder power during:

Base case

5-min response to low frequency deviation

10-min response to low frequency deviation

15-min response to low frequency deviation

Except during the relatively short response period, aggregate load behavior is unaffected. 


\section{Frequency power response}

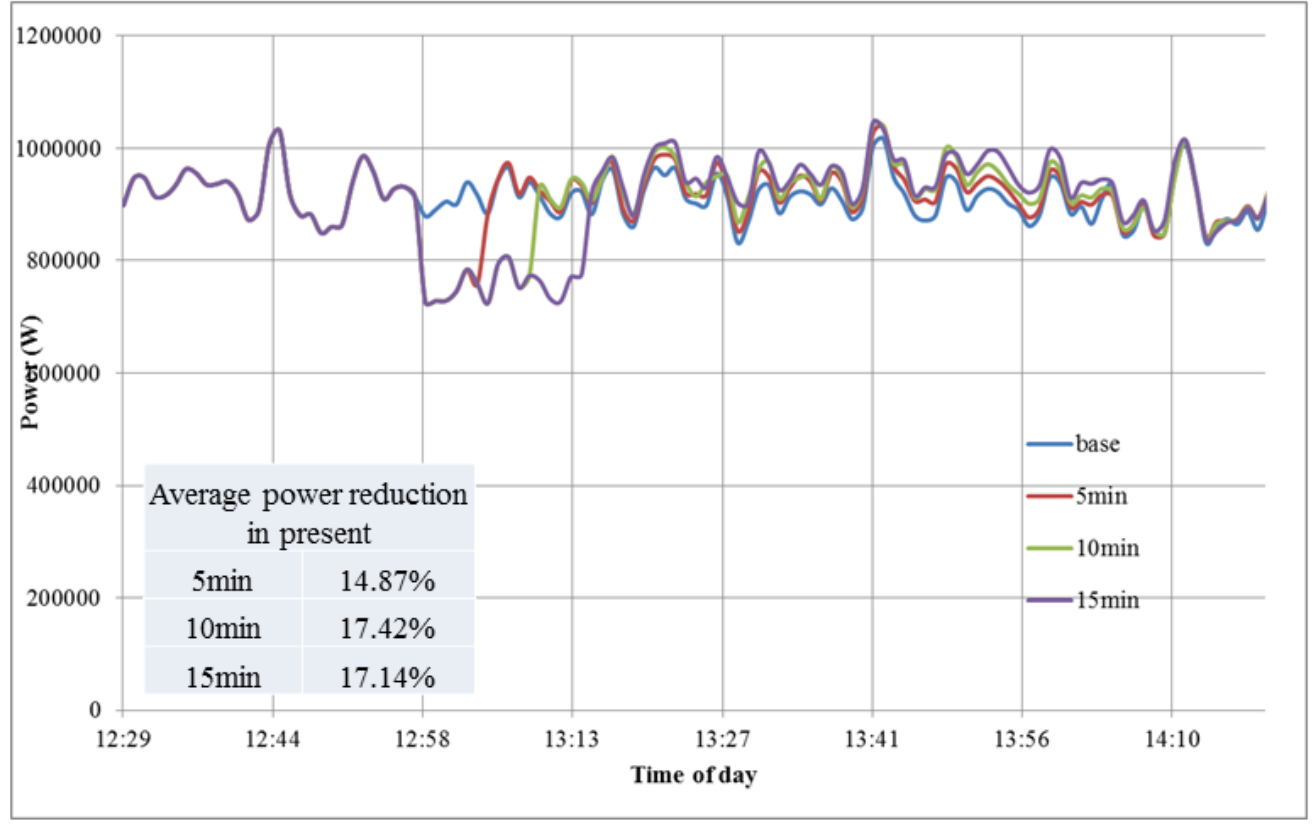

For 5,10 and 15 min intervals

\section{NOTES:}

Zoomed in portion of the previous graphic. 


\section{Aggregate load behavior when using frequency control}

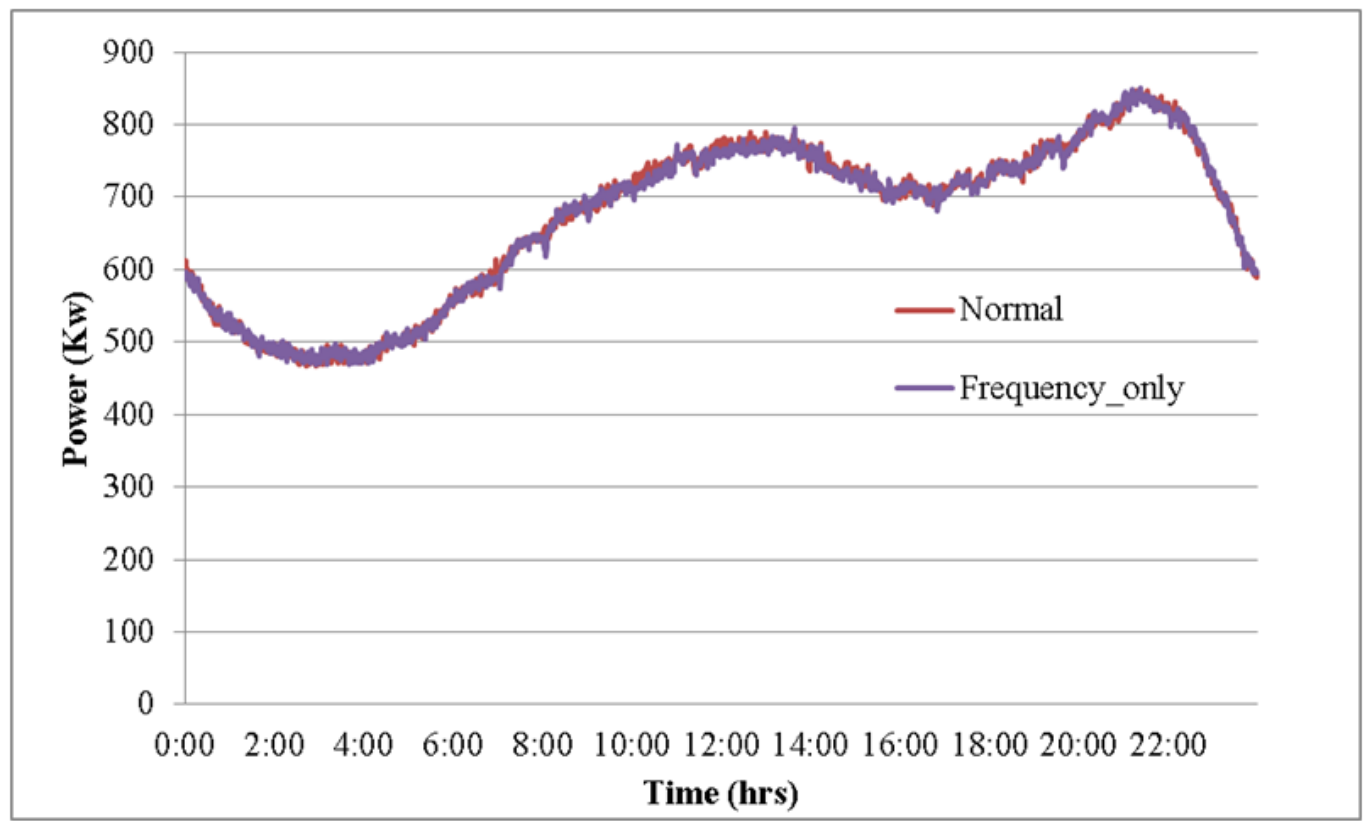

\section{NOTES:}

The long term load behavior is basically unaffected due to the short response time required for frequency regulation. 


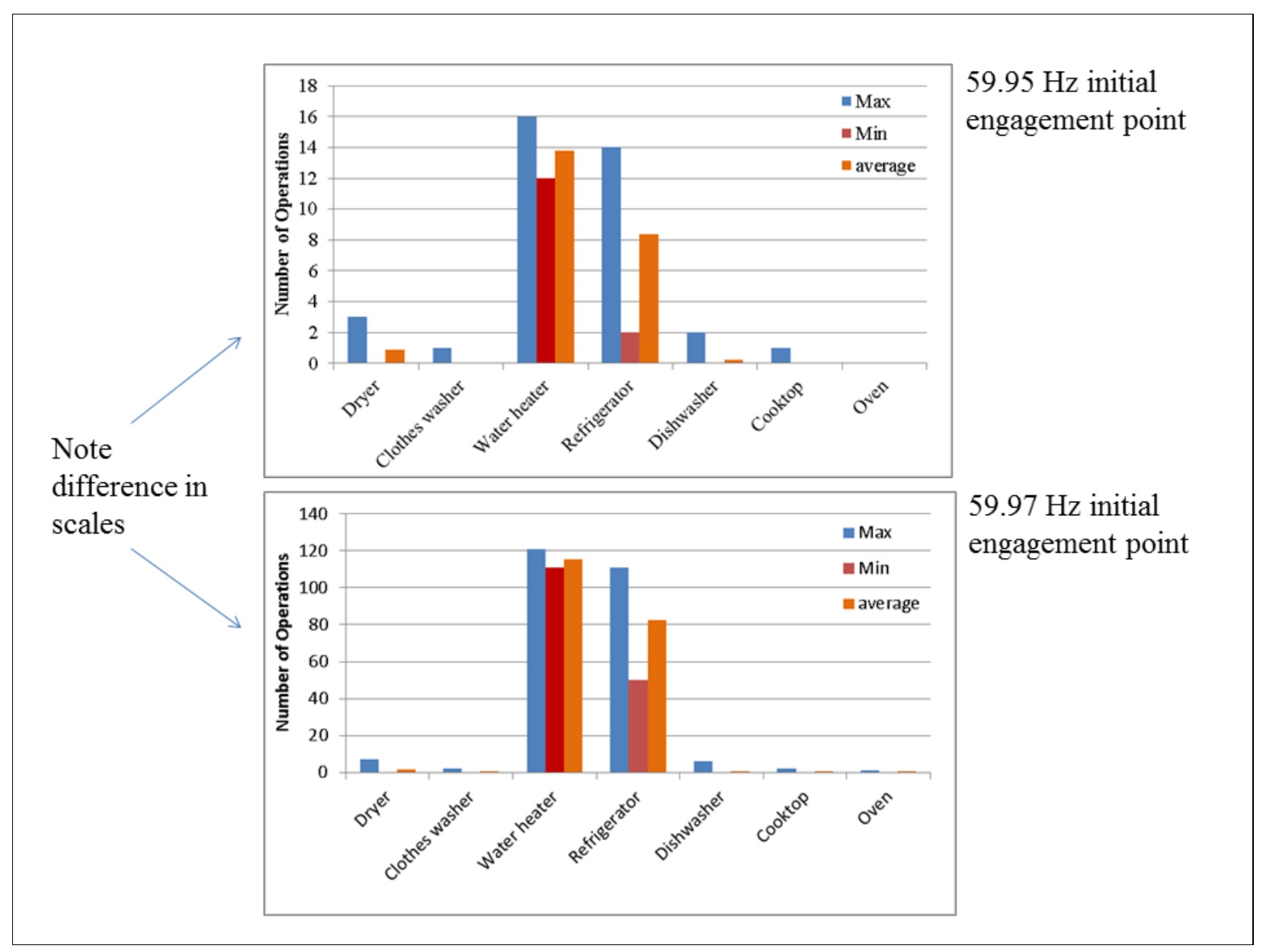

\section{NOTES:}

Setting your response limits greatly effects how often the appliances respond. Much more work needs to be done to understand how often is acceptable and what the proper set points might be. A hybrid approach may let them respond and detect locally/anonymously, while the setpoint is modified from a central controller on a much greater time scale than the response itself (e.g., modify setpoint every 15 minutes but respond on 5-10 sec level).

Note that water heaters and refrigerators provide the most response, mainly due to (1) the greater relative "on" time of refrigerators and (2) the relative ease in which water heaters are able to respond to short time frames.

These plots are responding to actual low frequency "events" in PJM market over the course of a one month period. When the engagement point was set to $59.93 \mathrm{~Hz}$, no responses were seen (i.e., frequency never dropped below $59.93 \mathrm{~Hz}$ ).

An "operation" corresponds to a 5-minute reduction in load. 


\section{Voltage controller}

\section{NOTES:}

The goal of this control method is to reduce demand during periods of low system voltage using only local sensing. Low voltage periods may be driven by peak load demand and heavy loading of the feeder, or, in this case, driven by high penetration solar photovoltaic and a sudden passage of cloud ("cloud transient") that quickly reduces the solar power output. A simple deadband control was devised to operate the appliances in energy reduction modes during low voltage periods. Initial indications were that because voltage fluctuations are localized and not necessarily co-dependent with appliance operation, appliances were not able to provide significant benefits (less than a $0.5 \mathrm{~V}$ change in voltage at the consumer meter). However, if devices were operated in a more coordinated manner (rather than purely local, autonomous control), more benefits may be achieved. However, more work is needed in this area to determine this. 


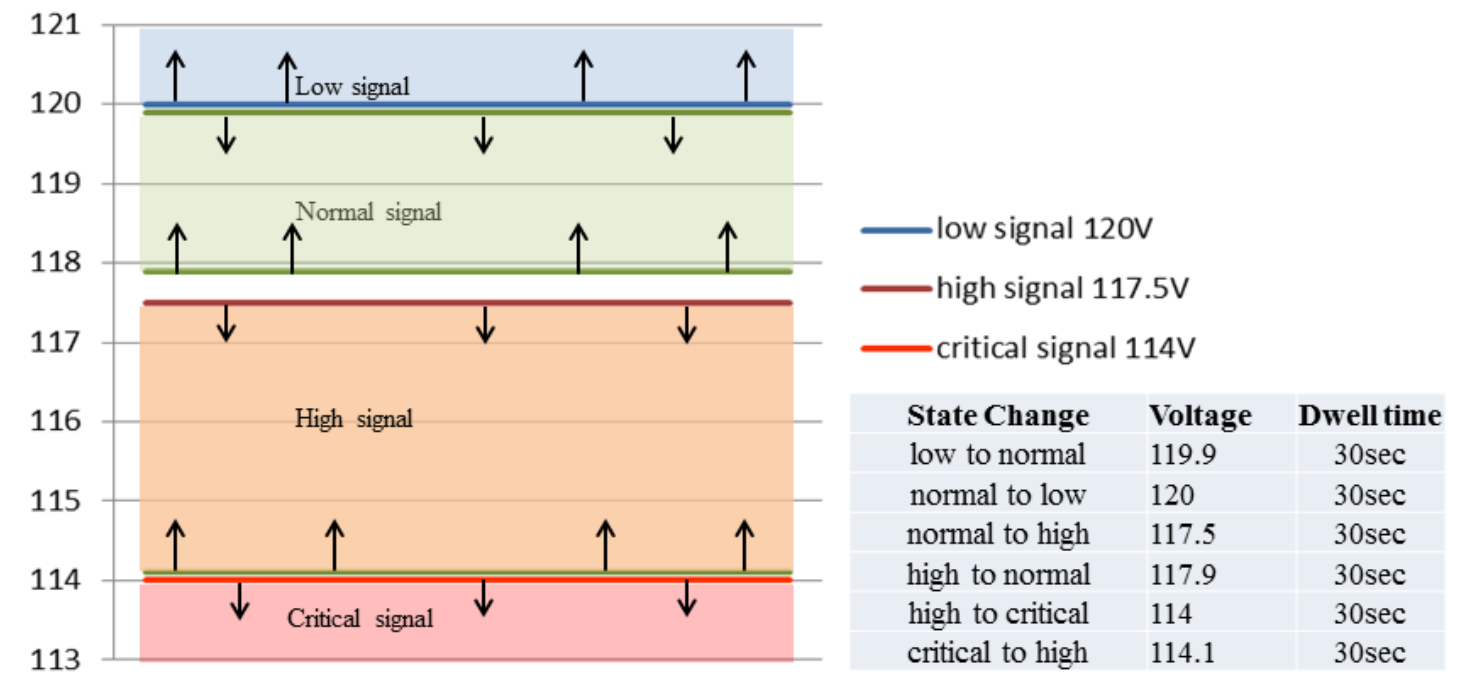

\section{NOTES:}

Dead band for low $0.1 \mathrm{v}$ below set point, dead band for high to normal $0.4 \mathrm{v}$ above set point, dead band for critical to high $0.1 \mathrm{v}$ above set point

Moving these control points around has a great effect on how often the appliances react. The control setpoints may need to be different for different locations. However, this is used to show the POSSIBILITIES of local control in a very simple manner, and determine whether appliances can even be effective at managing voltage. 


\section{Can alleviate voltage problems}

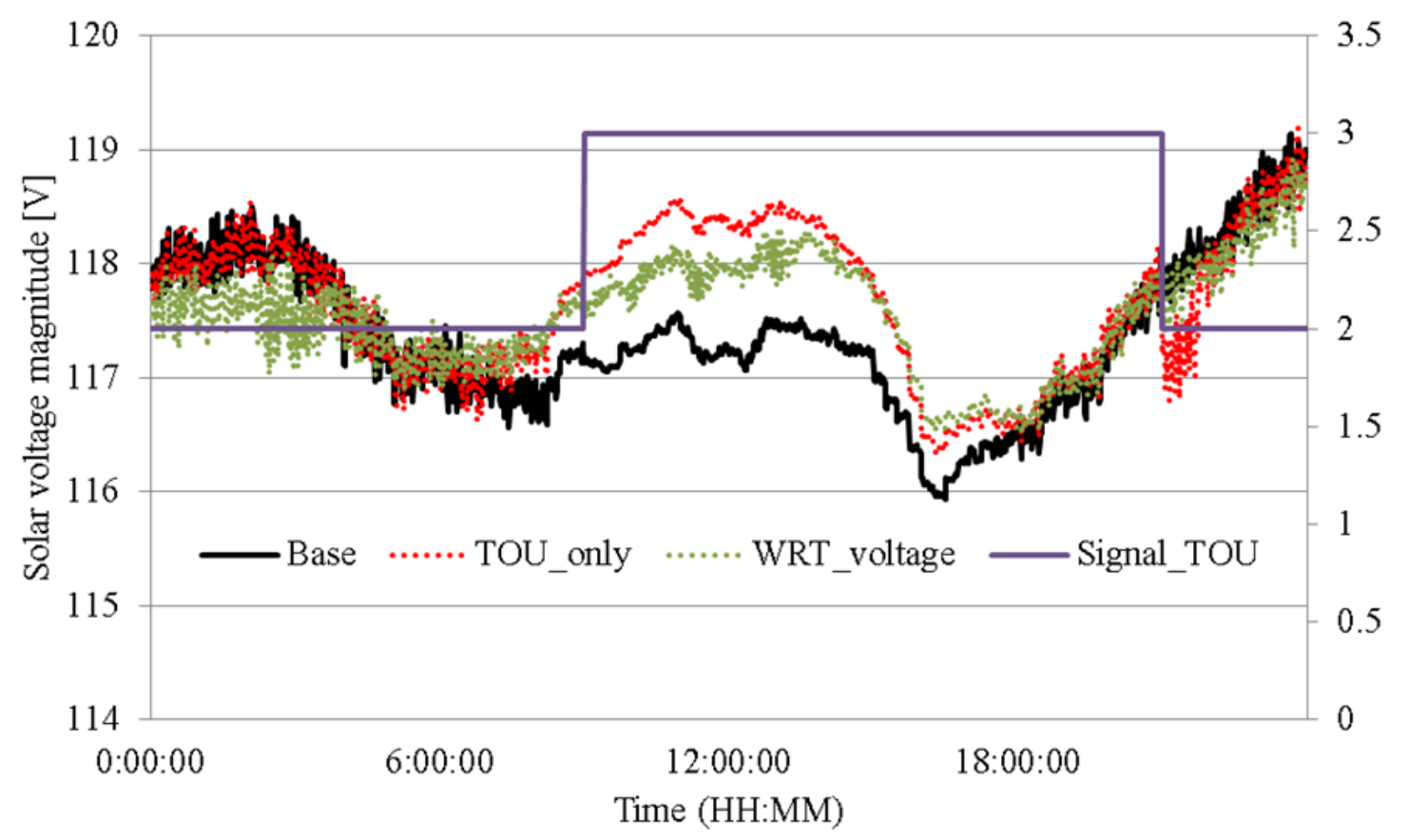

NOTES:

In this case, the "base" case is one where the distribution feeder regulator taps are set for high solar penetration, i.e., lower voltage than on standard feeders. Because of a cloudy day, voltage at a home creeps towards the ANSI band (not really close in this case, but representative). By locally sensing voltage, appliances reduce demand to maintain voltage at a higher level. 


\section{Voltage controller solar penetration and appliance acceptance}

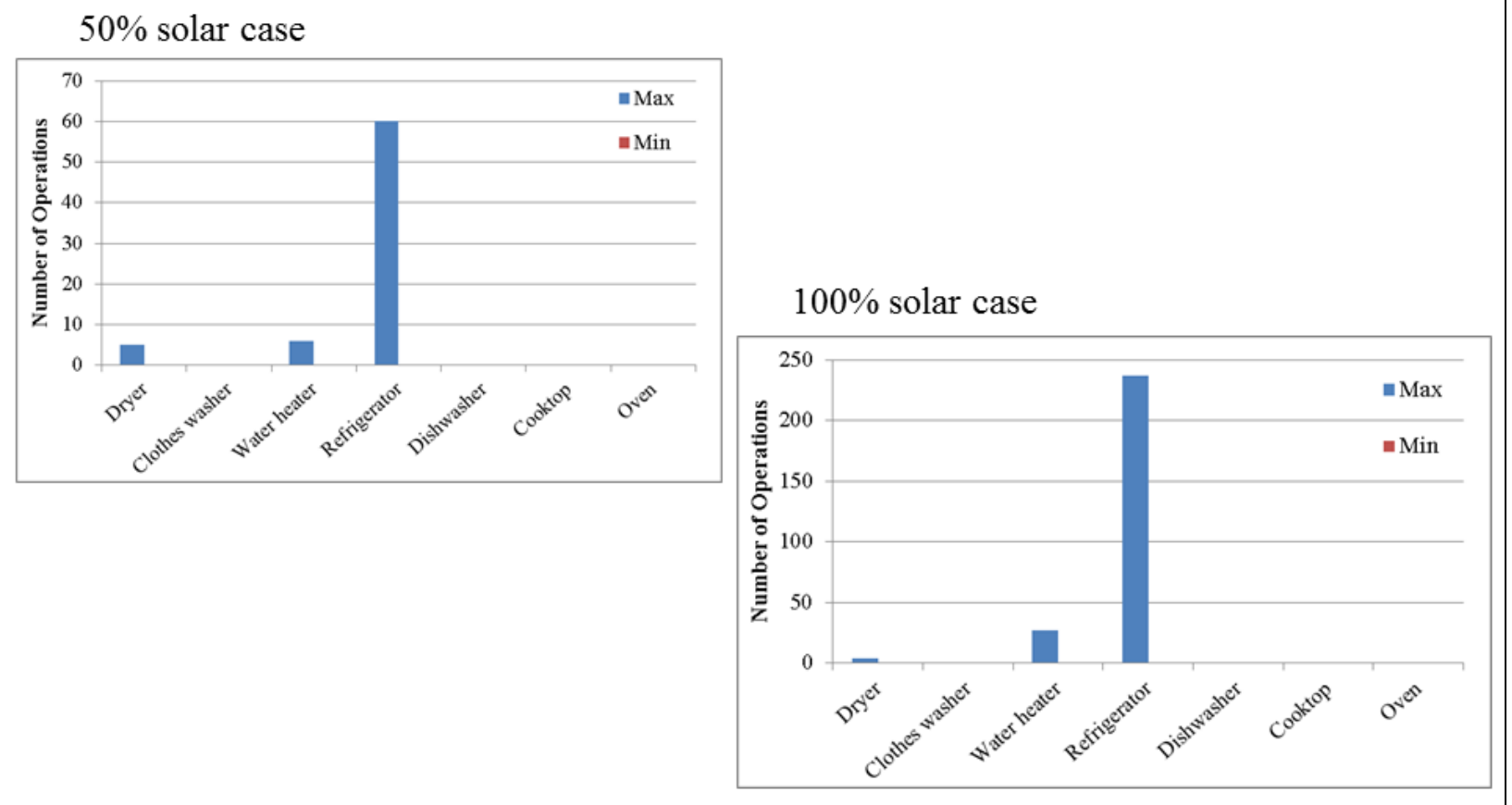

\section{NOTES:}

Different solar penetration levels (or voltage control sensitivity) will affect how often the appliances are engaged in short term voltage response. From 50\% to $100 \%$ penetration, the refrigerator went from 60 responses to 240. In general, water heaters and refrigerators respond far more often due to higher availability.

The "tuning" of the control has an effect on the number of appliance operations that may affect the lifetime of the appliance.

NOTE: Minimum is zero in all cases, and the "average" appliance response rate is effectively zero. This may be an opportunity for utility diagnostics to identify low (or high) voltage points on the system by collecting the \# of operations. 


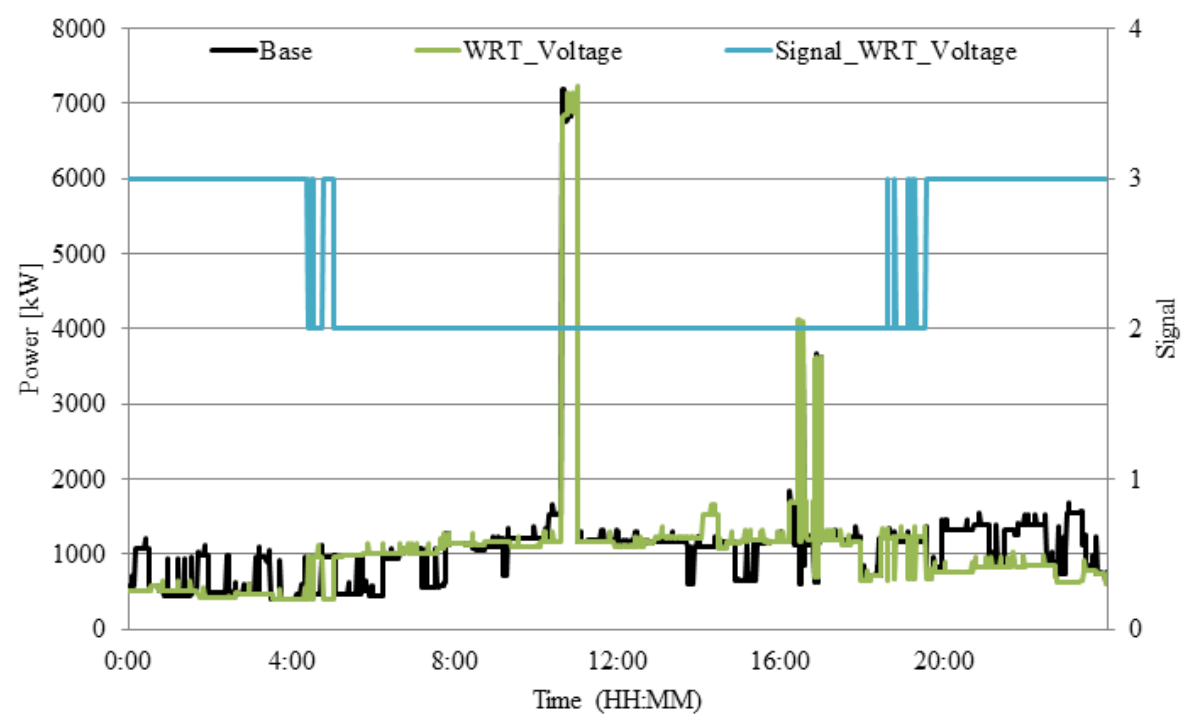

\section{NOTES:}

A single household responds to voltage "signal" by shifting load during low voltage periods to other. Because the voltage transients are fairly short, load behavior is relatively unaffected from a consumer's perspective. 


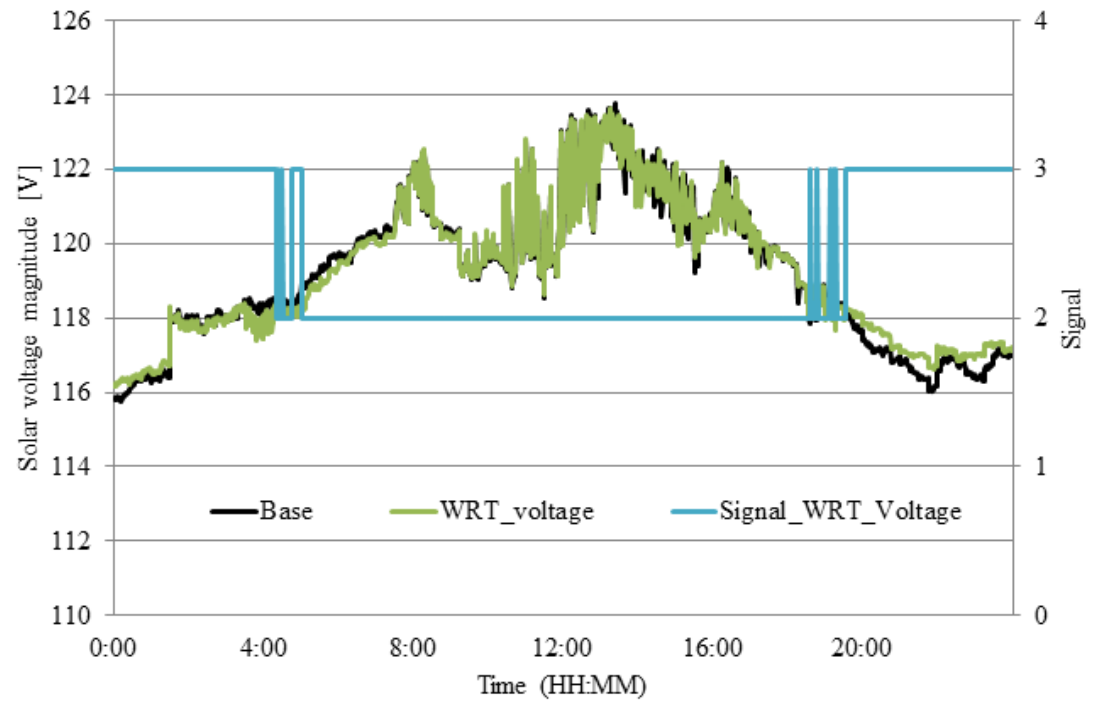

\section{NOTES:}

Unfortunately, modifying "real" power does not affect voltage significantly. Notice that full response after 19:00 only increases voltage by $1 / 2$ volt. This requires a lot of change in real power to affect voltage. 


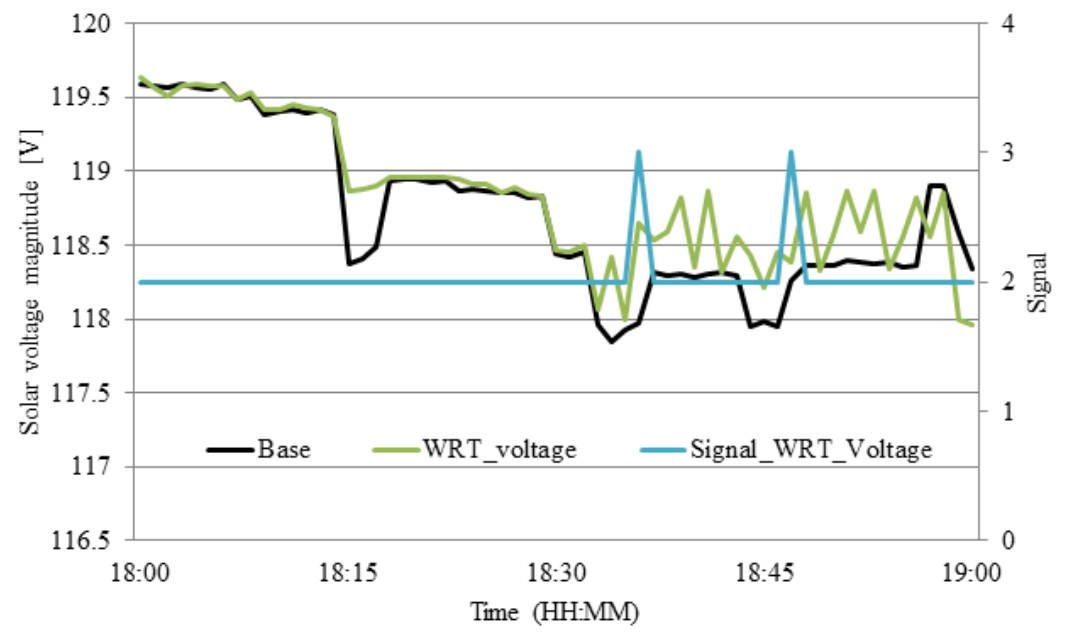

NOTES:

Zoom-in of previous graphic. 


\section{Voltage controller and tap changes for different solar penetrations}

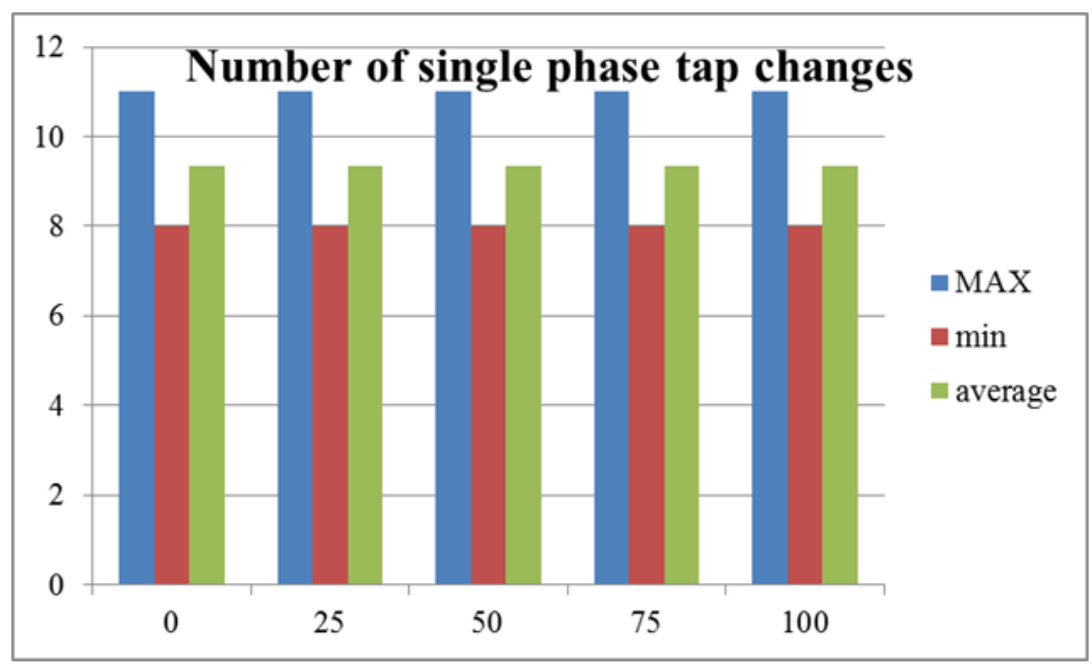

\section{NOTES:}

At different penetration levels of solar, normally we might see a significant change in regulator tap positions. The local appliance control reduces the affect and may maintain regulator maintenance cycles and lifetimes.

Part of this is due to the fact that most regulators do not look "downstream" but rather locally to maintain control due to an assumption of "downstream" power flow. 


\section{Aggregate Behavior with Voltage Control}

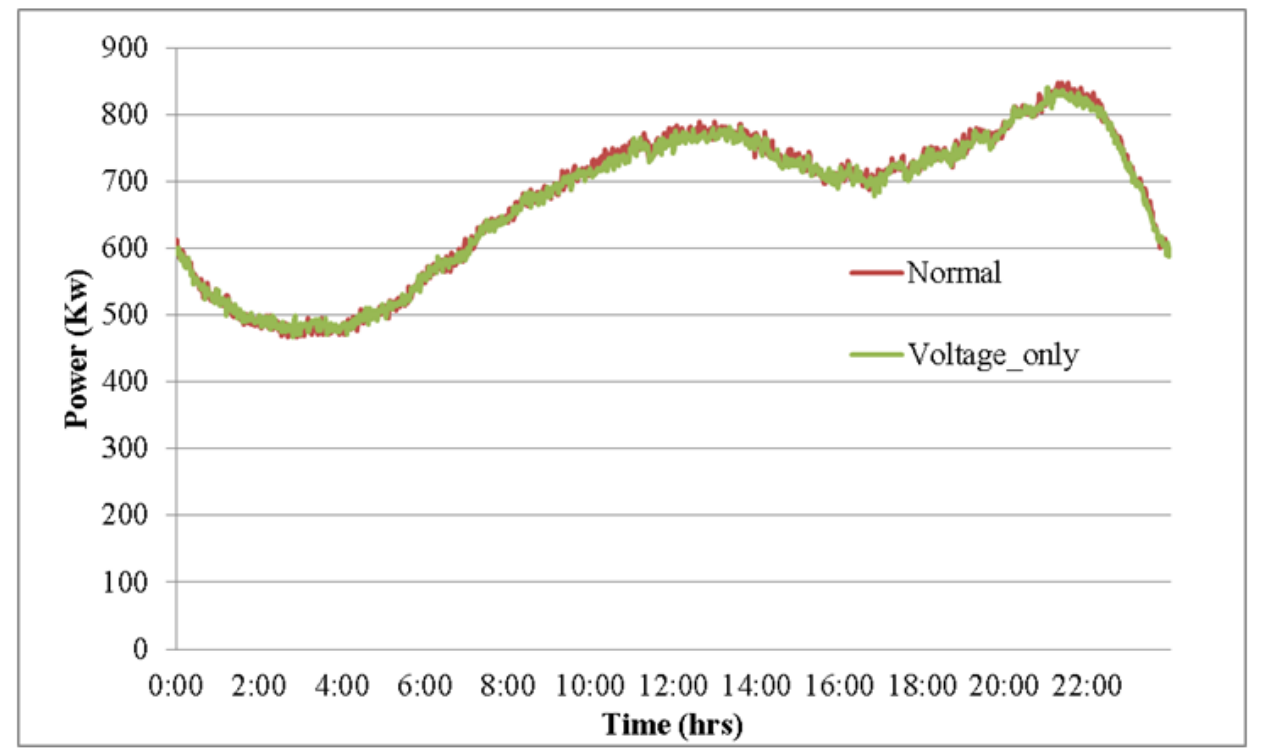

\section{NOTES:}

The aggregate load behavior is mostly unaffected as the localized voltage control modifies behavior for a relatively short amount of time. 


\begin{tabular}{|c|c|c|c|}
\hline TOU & Voltage & W.R.T. Voltage & W.R.T. TOU \\
\hline Normal & Normal & Normal & Normal \\
\hline Normal & High & High & Normal \\
\hline Normal & Critical & High & High \\
\hline High & Normal & Normal & High \\
\hline High & High & High & High \\
\hline High & Critical & Critical & High \\
\hline Critical & Normal & High & High \\
\hline Critical & High & High & Critical \\
\hline Critical & Critical & Critical & Critical \\
\hline
\end{tabular}

\section{NOTES:}

You can perform single functions (TOU or Voltage control) or mix them and weight them appropriate to the system needs - WRT voltage indicates weighting is more towards the voltage control and less towards TOU.

Additionally, frequency control can be mixed into these. Much research is needed to understand what the balance between different goals might be (i.e., how often should you respond to voltage signals vs. frequency vs. energy prices vs. a whole slew of other possibilities). In some cases, for example voltage control and most other forms of localized benefits, there is no current mechanism for incentivizing customers to respond. New incentive programs or market-like constructs may be needed to encourage customer participation. 
PNNL-22204

\section{Distribution}

No. of

\section{Copies}

1 Dan Ton

U.S. Department of Energy 1000 Independence Avenue, SW Washington, DC 20585

GE Appliances and Light

Address

City, State and ZIP Code

1 William Burke

GE Appliances and Light

Address

City, State and ZIP Code
No. of

\section{Copies}

5 Local Distribution

Pacific Northwest National Laboratory

GB Parker

K6-05

$\mathrm{CH}$ Imhoff

K9-69

DA King

K2-12

RG Pratt

K1-85

JC Fuller

K1 


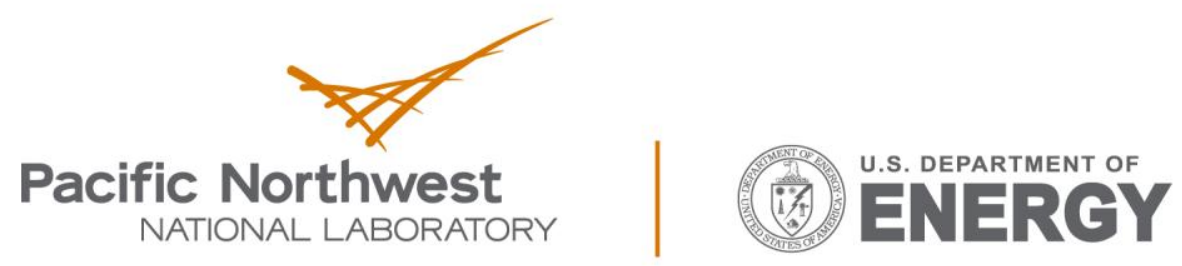

Proudly Operated by Battelle Since 1965

902 Battelle Boulevard

P.O. Box 999

Richland, WA 99352

1-888-375-PNNL (7665)

www.pnnl.gov 